\title{
Association between hemoglobin within the normal range and hemoglobin A1C among Chinese non-diabetes adults
}

Yi Lai ${ }^{1}$, Zhihong Lin ${ }^{2}$ and Zhongxin Zhu ${ }^{3,4^{*}}$ (D)

\begin{abstract}
Background: Hemoglobin A1c ( $\mathrm{HbA1c}$ ) is the product of a non-enzymatic chemical reaction between hemoglobin $(\mathrm{Hb})$ and glucose. However, the association between $\mathrm{Hb}$ and $\mathrm{HbA} 1 \mathrm{c}$ remains to be fully elucidated in view of the controversial findings reported to date. Therefore, our aim in this study was to evaluate the association between $\mathrm{Hb}$ levels within the normal range and $\mathrm{HbA1c}$ levels among Chinese non-diabetes adults using cross-sectional data from the China Health and Nutrition Survey 2009.

Methods: Our analysis was based on the data of 1659 non-diabete adults 20-49 years of age. Multivariable linear models were applied to examine the association between $\mathrm{Hb}$ and $\mathrm{HbA} 1 \mathrm{c}$ levels. Subgroup analyses stratified by age and sex were also performed.

Results: The association between $\mathrm{Hb}$ and $\mathrm{HbA} 1 \mathrm{c}$ levels was positive in the unadjusted model ( $\beta=0.020,95 \% \mathrm{Cl}$ : $0.008,0.032$ ). However, this association did not remain significant when the regression model was minimally adjusted for age and sex ( $\beta=0.006,95 \% \mathrm{Cl}$ : $-0.014,0.024)$; this association became negative when the model was further adjusted for covariates whose effect estimates of $\mathrm{HbA} 1 \mathrm{c}$ levels more than $10 \%$ ( $\beta=-0.042,95 \% \mathrm{Cl}:-0.064$, -0.020 ). The association remained negative on subgroup analyses stratified by age ( $20-34$ years: $\beta=-0.052,95 \%$ Cl: $-0.091,-0.013 ; 35-49$ years: $\beta=-0.041,95 \% \mathrm{Cl}:-0.068,-0.014)$ and sex (men: $\beta=-0.042,95 \% \mathrm{Cl}:-0.074,-$ 0.010; women: $\beta=-0.042,95 \% \mathrm{Cl}:-0.073,-0.012)$ when controlling for covariates.
\end{abstract}

Conclusions: Our findings revealed that $\mathrm{Hb}$ levels within the normal range were negatively associated with $\mathrm{HbA} 1 \mathrm{c}$ levels among Chinese non-diabetes adults. Confounding factors, such as red blood cell counts can affect the association between $\mathrm{Hb}$ and $\mathrm{HbA} 1 \mathrm{c}$ levels.

Keywords: Hemoglobin, Hemoglobin A1c, Diabetes, Biomarker, China health and nutrition survey

\footnotetext{
*Correspondence: orthozzx@163.com

${ }^{3}$ Department of Osteoporosis Care and Control, Xiaoshan Affiliated Hospital of Wenzhou Medical University, Hangzhou 311200, Zhejiang, China

${ }^{4}$ Clinical Research Center, Xiaoshan Affiliated Hospital of Wenzhou Medical University, Hangzhou 311200, Zhejiang, China

Full list of author information is available at the end of the article
}

C C The Author(s). 2021 Open Access This article is licensed under a Creative Commons Attribution 4.0 International License, which permits use, sharing, adaptation, distribution and reproduction in any medium or format, as long as you give appropriate credit to the original author(s) and the source, provide a link to the Creative Commons licence, and indicate if changes were made. The images or other third party material in this article are included in the article's Creative Commons. licence, unless indicated otherwise in a credit line to the material. If material is not included in the article's Creative Commons licence and your intended use is not permitted by statutory regulation or exceeds the permitted use, you will need to obtain permission directly from the copyright holder. To view a copy of this licence, visit http://creativecommons.org/licenses/by/4.0/ The Creative Commons Public Domain Dedication waiver (http://creativecommons.org/publicdomain/zero/1.0/) applies to the data made available in this article, unless otherwise stated in a credit line to the data. 


\section{Background}

Diabetes is one of the most prevalent diseases globally. Almost $10 \%$ of the world's adult population (nearly 500 million individuals) live with diabetes, with the prevalence expected to increase to 700 million by 2045 [1]. Moreover, although the prevalence of diabetes is high, nearly half of the individuals living with diabetes are unaware of their disease status [2]. If left untreated, diabetes is associated with devastating short- and long-term complications [3]. As early interventions might delay or even prevent full-blown diabetes, it is important to identify individuals at high risk of diabetes. Accordingly, ongoing studies are assessing the utility of novel and less studied biomarkers of diabetes [4].

Hemoglobin $(\mathrm{Hb})$, a protein only found in red blood cells, becomes glycated or coated with glucose from the bloodstream. As the extent of $\mathrm{Hb}$ glycation is influenced by the amount of blood glucose, increased blood glucose levels are reflected on the surface of the $\mathrm{Hb}$ protein [5]. Hemoglobin A1c (HbA1c) is the product of a nonenzymatic chemical reaction between $\mathrm{Hb}$ and glucose [6]. The HbA1c level reflects the average level of blood glucose over the past 90 days [7]. As a measure of blood glucose, HbA1c has several advantages over fasting plasma glucose generally used in practice: greater convenience as no fasting is required; greater pre-analytical stability; and less day-to-day variability due to stress, diet, or illness [8]. However, previous studies that focused on the relationship between $\mathrm{Hb}$ and $\mathrm{HbA} 1 \mathrm{c}$ in patients with anemia yielded inconsistent findings [9]. Moreover, the association between $\mathrm{Hb}$ levels within the normal range and $\mathrm{HbA1c}$ levels remains to be clarified. Therefore, our aim in this study was to evaluate the association between $\mathrm{Hb}$ levels within the normal range and HbA1c levels among Chinese non-diabetes adults using cross-sectional data from the China Health and Nutrition Survey (CHNS).

\section{Methods}

\section{Study population}

The CHNS is an ongoing, open, population-based study conducted by the National Institute for Nutrition and Food Safety at the Chinese Center for Disease Control and Prevention (CCDC) and the Carolina Population Center at the University of North Carolina at Chapel Hill (UNC), designed to examine the health and nutrition status of the Chinese population [10]. In 2009, the Department of Laboratory Medicine of China-Japan Friendship Hospital, Ministry of Health joined this project as the lead agency for the collection, storage and analysis of biospecimens. The CHNS protocols were approved by the Institutional Review Board of National Institute of Nutrition and Food Safety at Chinese Center for Disease Control and Prevention, the Carolina Population Center at the University of North Carolina at Chapel Hill, and the China-Japan Friendship Hospital, Ministry of Health, China. All participants provided written informed consent for the use of their data in research.

A total of 10 waves of the survey have been conducted since 1989. Notably, blood samples were collected as part of the CHNS for the first time in the 2009 survey. In this study, 3926 adults aged 20-49 years, with available data on both $\mathrm{Hb}$ and $\mathrm{HbA1c}$ levels were deemed eligible. We excluded individuals with missing weight or height data $(n=1804)$; a diagnosis of diabetes $(n=28)$, an HbA1c level $\geq 6.5 \% \quad(n=85)$, or glucose level $\geq 7.0$ $\mathrm{mol} / \mathrm{L}(n=28)$; and a $\mathrm{Hb}$ level outside the normal range $(n=322)$. The data for the remaining 1659 non-diabetes adults were included in our final analysis (Fig. 1).

\section{Study variables}

In the CHNS, blood samples $(12 \mathrm{~mL})$ were collected after overnight fasting for $>8$ hours, and analyzed under strict quality control at the Beijing central laboratory as per previously described methods, using a 3- or 5-part classification automated hematology analyzer (Hitachi 7600 automated analyzer, Hitachi Inc., Japan) [11].

The $\mathrm{Hb}$ level, considered as the variable of exposure in our study, was determined by the volume, conductivity, and scatter method for blood cell analysis using the LH750 hematology analyzer (Beckman Coulter, USA). The normal range for Hb levels is $13.3-17.7 \mathrm{~g} /$ $\mathrm{dL}$ for adult men and 11.7-15.7 g/dL for adult women [12]. The HbA1c level, defined as the outcome variable, was measured using high-performance liquid

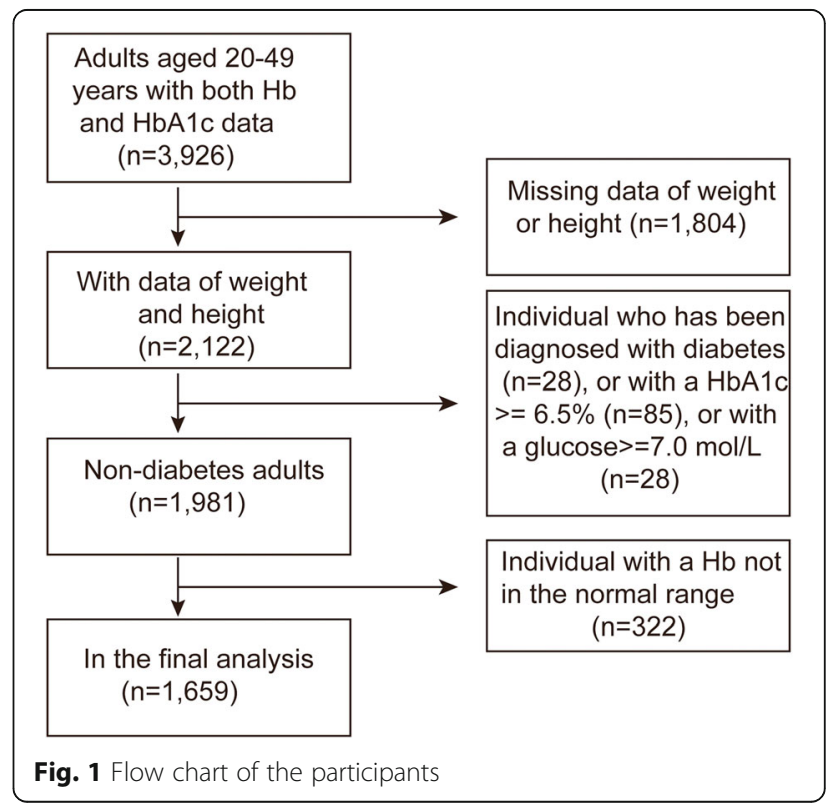


chromatography using a National Glycohemoglobin Standardization Program certified automated analyzer (model HLC-723 G7, Japan). The level of fasting plasma glucose was measured using the GOD-PAP method (Randox Laboratories Ltd., UK). Diabetes was defined as an HbA1c level $\geq 6.5 \%$ or a fasting plasma glucose level $\geq 7.0 \mathrm{mmol} / \mathrm{L}$, following the 2019 American Diabetes Association criteria [13].

Data on the following covariates were extracted for inclusion in our analysis: age, sex, ethnicity, education level, activities (based on the question "How much do you like to participate in this activity"), smoking behavior, alcohol consumption, body mass index (BMI), total protein, total cholesterol, blood glucose, alanine aminotransferase (ALT), uric acid, serum creatinine, white blood cell (WBC) count, red blood cell (RBC) count, and platelet (PLT) count. Details regarding the acquisition process of data on $\mathrm{Hb}$ levels, $\mathrm{HbA1c}$, and other covariates have been previously described in detail [14].

\section{Statistical analysis}

All analyses were performed using statistical software $\mathrm{R}$ (version 3.4.3) and EmpowerStats (X\&Y Solutions, Boston, $\mathrm{MA})$. Between-group differences were evaluated using

Table 1 The characteristics of participants

\begin{tabular}{|c|c|c|c|}
\hline & Men $(n=781)$ & Women $(n=878)$ & $P$ value \\
\hline Age (years) & $37.70 \pm 8.01$ & $38.07 \pm 7.67$ & 0.335 \\
\hline Ethnicity (\%) & & & 0.883 \\
\hline Han population & 92.45 & 92.60 & \\
\hline Non- Han population & 6.79 & 6.83 & \\
\hline Not recorded & 0.77 & 0.57 & \\
\hline Education level (\%) & & & $<0.001$ \\
\hline None or grad from primary & 14.85 & 26.54 & \\
\hline Middle school degree & 60.82 & 52.73 & \\
\hline More than middle school & 18.82 & 15.95 & \\
\hline Not recorded & 5.51 & 4.78 & \\
\hline Activities (\%) & & & $<0.001$ \\
\hline Dislike & 59.41 & 67.08 & \\
\hline Neutral & 21.00 & 21.87 & \\
\hline Like & 19.59 & 11.05 & \\
\hline Smoking behavior (\%) & & & $<0.001$ \\
\hline No & 38.41 & 97.95 & \\
\hline Yes & 61.59 & 2.05 & \\
\hline Alcohol consumption (\%) & & & $<0.001$ \\
\hline No & 32.78 & 91.23 & \\
\hline Yes & 67.22 & 8.77 & \\
\hline Body mass index $\left(\mathrm{kg} / \mathrm{m}^{2}\right)$ & $23.92 \pm 3.33$ & $23.38 \pm 3.32$ & $<0.001$ \\
\hline Total protein $(\mathrm{g} / \mathrm{L})$ & $76.21 \pm 4.65$ & $77.06 \pm 4.79$ & $<0.001$ \\
\hline Total cholesterol (mmol/L) & $4.66 \pm 0.93$ & $4.46 \pm 0.86$ & $<0.001$ \\
\hline Blood glucose (mmol/L) & $5.00 \pm 0.61$ & $4.92 \pm 0.55$ & 0.004 \\
\hline Alanine aminotransferase $(\mathrm{U} / \mathrm{L})$ & $29.52 \pm 21.56$ & $19.83 \pm 21.57$ & $<0.001$ \\
\hline Uric acid (umol/L) & $347.59 \pm 90.04$ & $232.58 \pm 60.62$ & $<0.001$ \\
\hline Serum creatinine (umol/L) & $91.66 \pm 10.97$ & $74.07 \pm 8.73$ & $<0.001$ \\
\hline White blood cell count $\left(10^{9} / \mathrm{L}\right)$ & $6.63 \pm 1.77$ & $6.20 \pm 1.86$ & $<0.001$ \\
\hline Red blood cell count $\left(10^{12} / \mathrm{L}\right)$ & $5.09 \pm 0.43$ & $4.50 \pm 0.40$ & $<0.001$ \\
\hline Platelet count $\left(10^{9} / \mathrm{L}\right)$ & $222.33 \pm 60.93$ & $233.84 \pm 57.74$ & $<0.001$ \\
\hline Hemoglobin (g/dL) & $15.60 \pm 0.95$ & $13.37 \pm 0.88$ & $<0.001$ \\
\hline Hemoglobin A1c (\%) & $5.51 \pm 0.37$ & $5.45 \pm 0.36$ & $<0.001$ \\
\hline
\end{tabular}

Mean \pm SD for continuous variables: $P$ value was calculated by one-way ANOVA (normal distribution) and Kruskal-Wallis $\mathrm{H}$ (skewed distribution) test $\%$ for categorical variables: $P$ value was calculated by chi-square test 
one-way ANOVA (normal distribution) and KruskalWallis $\mathrm{H}$ (skewed distribution) tests for continuous variables and a chi-squared test for categorical variables. The association between $\mathrm{HbAlc}$ and $\mathrm{Hb}$ levels was evaluated using multivariate linear regression analyses, with the creation of three models: an unadjusted model; minimally adjusted model, controlling for age and sex; and a fully adjusted model, controlling for age, sex, smoking behavior, alcohol consumption, BMI, blood glucose, WBC count, and $\mathrm{RBC}$ count. We selected these confounders on the basis of their effect estimates of more than $10 \%$. Supplementary Table 1 shows the associations of each covariate with HbA1c. The Hb level was categorized into quartiles; a sensitivity analysis as performed, and the $P$-value of the trend was calculated. Next, we performed subgroup analyses stratified by age and sex. We further used generalized additive models and smooth curve fittings to explore potential non-linearity in the association between $\mathrm{Hb}$ and HbA1c levels. A $P$-value $<0.05$ was considered significant for these analyses.

\section{Results}

Baseline characteristics for our study group, which included 781 men and 878 women, are presented in Table 1. Men had higher levels of education, and a higher BMI than women. Men had higher total cholesterol, blood glucose, ALT, uric acid, serum creatinine, WBC, RBC, Hb, and HbA1c values but lower total protein, and PLT values. Furthermore, the proportions of men who liked activity, smoked, and consumed alcohol were higher than those of women ( $p<0.05$ for each).

The association between $\mathrm{Hb}$ and $\mathrm{HbAlc}$ levels was positive in the unadjusted model $(\beta=0.020,95 \% \mathrm{CI}$ : $0.008,0.032$ ). However, this association was no longer significant after controlling for age and sex in the minimally adjusted model ( $\beta=0.006,95 \%$ CI: $-0.014,0.024)$, and became negative in the fully adjusted model $(\beta=-$
0.042, 95\% CI: $-0.064,-0.020)$, with a P for trend of < 0.001 . The results are presented in Table 2 .

As shown in Table 3, after controlling for potential confounding factors, the association between $\mathrm{Hb}$ and $\mathrm{Hb}$ A1c levels remained negative in the subgroup analyses stratified by age $(20-34$ years: $\beta=-0.052,95 \%$ CI: $0.091,-0.013$; $35-49$ years: $\beta=-0.041,95 \%$ CI: -0.068 , -0.014 ) and sex (men: $\beta=-0.042,95 \%$ CI: -0.074 , 0.010; women: $\beta=-0.042,95 \% \mathrm{CI}:-0.073,-0.012$ ). The results of generalized additive models and smooth curve fittings further confirmed this inverse associaton between $\mathrm{Hb}$ and HbA1c levels (Figs. 2, 3, 4).

\section{Discussion}

In this study, we evaluated a large sample of Chinese non-diabetes adults to explore the association between $\mathrm{Hb}$ levels within the normal range and HbA1c levels. Our results showed that $\mathrm{Hb}$ levels were independently and negatively associated with $\mathrm{HbA1c}$ levels in both men and women.

Anemia is a common condition, clinically defined as a hematocrit value or blood $\mathrm{Hb}$ level that is below the normal range. Anemia is often associated with diabetes and is known to increase the risk of diabetes-related complications [15]. However, previous studies that investigated the association between $\mathrm{Hb}$ and $\mathrm{HbA1c}$ levels in patients with anemia have yielded contradictory conclusions. While several studies have reported that HbA1c level was significantly higher in individuals with anemia [16-18], others did not identify a difference in HbA1c levels between individuals with anemia and healthy controls [19], or found a lower HbA1c level in patients with anemia [20].

Recently, Grossman et al. [21] conducted a large retrospective cohort study including 11,352 elderly nondiabetic community individuals to evaluate the association between $\mathrm{Hb}$ and $\mathrm{HbA1c}$ levels. Although they found that

Table 2 Association between hemoglobin level ( $\mathrm{g} / \mathrm{dL}$ ) and hemoglobin A1c level (\%)

\begin{tabular}{llll}
\hline & $\begin{array}{l}\text { Unadjusted model } \\
\boldsymbol{\beta}(\mathbf{9 5 \%} \mathrm{Cl})\end{array}$ & $\begin{array}{l}\text { Minimally adjusted model } \\
\boldsymbol{\beta}(\mathbf{9 5 \%} \mathrm{Cl})\end{array}$ & \multicolumn{1}{c}{$\begin{array}{l}\text { Fully adjusted model } \\
\boldsymbol{\beta} \mathbf{( 9 5 \% ~ C l )}\end{array}$} \\
\hline Hemoglobin & $0.020(0.008,0.032)^{* *}$ & $0.006(-0.014,0.024)$ & $-0.042(-0.064,-0.020)^{* * *}$ \\
Hemoglobin (Quartile) & & & Reference \\
Q1 & Reference & Reference & $-0.03(-0.08,0.02)$ \\
Q2 & $0.03(-0.02,0.08)$ & $0.02(-0.03,0.07)$ & $-0.07(-0.14,-0.01)$ \\
Q3 & $0.07(0.02,0.12)$ & $0.02(-0.04,0.09)$ & $-0.14(-0.22,-0.06)$ \\
Q4 & $0.07(0.02,0.12)$ & $0.01(-0.07,0.08)$ & $<0.001$ \\
\hline P for trend & 0.002 & 0.771 & \\
\hline
\end{tabular}

Unadjusted model: no covariates were adjusted

Minimally adjusted model: age and sex were adjusted

Fully adjusted model: age, sex, smoking behavior, alcohol consumption, body mass index, blood glucose, white blood cell count, and red blood cell count were adjusted

${ }^{*} P<0.05,{ }^{* *} P<0.01,{ }^{* * *} P<0.001$ 
Table 3 Association between hemoglobin $(\mathrm{g} / \mathrm{dL})$ and hemoglobin A1c (\%), stratified by age and sex

\begin{tabular}{llll}
\hline & $\begin{array}{l}\text { Unadjusted model } \\
\boldsymbol{\beta}(\mathbf{9 5 \%} \mathrm{Cl})\end{array}$ & $\begin{array}{l}\text { Minimally adjusted model } \\
\boldsymbol{\beta}(\mathbf{9 5 \%} \mathrm{Cl})\end{array}$ & \multicolumn{1}{c}{$\begin{array}{l}\text { Fully adjusted model } \\
\boldsymbol{\beta}(\mathbf{9 5 \%} \mathrm{Cl})\end{array}$} \\
\hline $\begin{array}{l}\text { Stratified by age } \\
\text { 20-34 years }\end{array}$ & $0.009(-0.011,0.030)$ & $-0.011(-0.043,0.022)$ & $-0.052(-0.091,-0.013)^{* *}$ \\
35-49years & $0.025(0.010,0.040)^{* *}$ & $0.012(-0.011,0.036)$ & $-0.041(-0.068,-0.014)^{* *}$ \\
Stratified by sex & & & $-0.042(-0.074,-0.010)^{* *}$ \\
Men & $-0.006(-0.033,0.022)$ & $-0.005(-0.032,0.023)$ & $-0.042(-0.073,-0.012)^{* *}$ \\
Women & $0.021(-0.006,0.047)$ & $0.016(-0.011,0.043)$ &
\end{tabular}

Unadjusted model: no covariates were adjusted

Minimally adjusted model: age and sex were adjusted

Fully adjusted model: age, sex, smoking behavior, alcohol consumption, body mass index, blood glucose, white blood cell count, and red blood cell count were adjusted

Sex is not adjusted in the subgroup analysis stratified by sex

${ }^{*} P<0.05,{ }^{* *} P<0.01,{ }^{* * *} P<0.001$

$\mathrm{Hb}$ levels were significantly lower among individuals in the highest HbA1c quintile than among individuals in the other quintiles, the correlation between $\mathrm{HbA} 1 \mathrm{c}$ and $\mathrm{Hb}$ levels was negligible. In our study, the correlation between $\mathrm{Hb}$ levels in the normal range and HbA1c levels was positive in the unadjusted model but became non-significant after adjusting for age and sex and became negative after adjustment for potential confounding factors. Differences in the reported association between $\mathrm{Hb}$ and $\mathrm{HbA1c}$ levels between studies might reflect the differences in study design and confounding variables used for adjustment.

The HbA1c test is easy to perform, making it widely available as an ideal tool for busy primary care and endocrine practices [22]. However, the HbA1c level is impacted by numerous factors, such as race, RBC disorders, and hemoglobinopathies [23]. Moreover, iron deficiency anemia may cause a spurious increase in $\mathrm{HbA1c}$ values [24]. Our findings supported an independent negative association between $\mathrm{Hb}$ and $\mathrm{HbA1c}$ levels among non-diabetes adults with normal $\mathrm{Hb}$ levels, with this relationship being stable in both men and women.

The main strength of our study was the large-scale, and population-based study design; approximately $56 \%$ of the Chinese population is covered by the CHNS. Therefore, our results can be generalized to the entire Chinese population. The limitations of our study also need to be acknowledged. First, the CHNS provides cross-sectional data, and therefore, the causal relationship between $\mathrm{Hb}$ and $\mathrm{HbA} 1 \mathrm{c}$ cannot be determined. A longitudinal study is warranted in this regard. Second, we excluded individuals with diabetes, with abnormal $\mathrm{Hb}$ values, and an age $>50$ years. Therefore, our conclusions
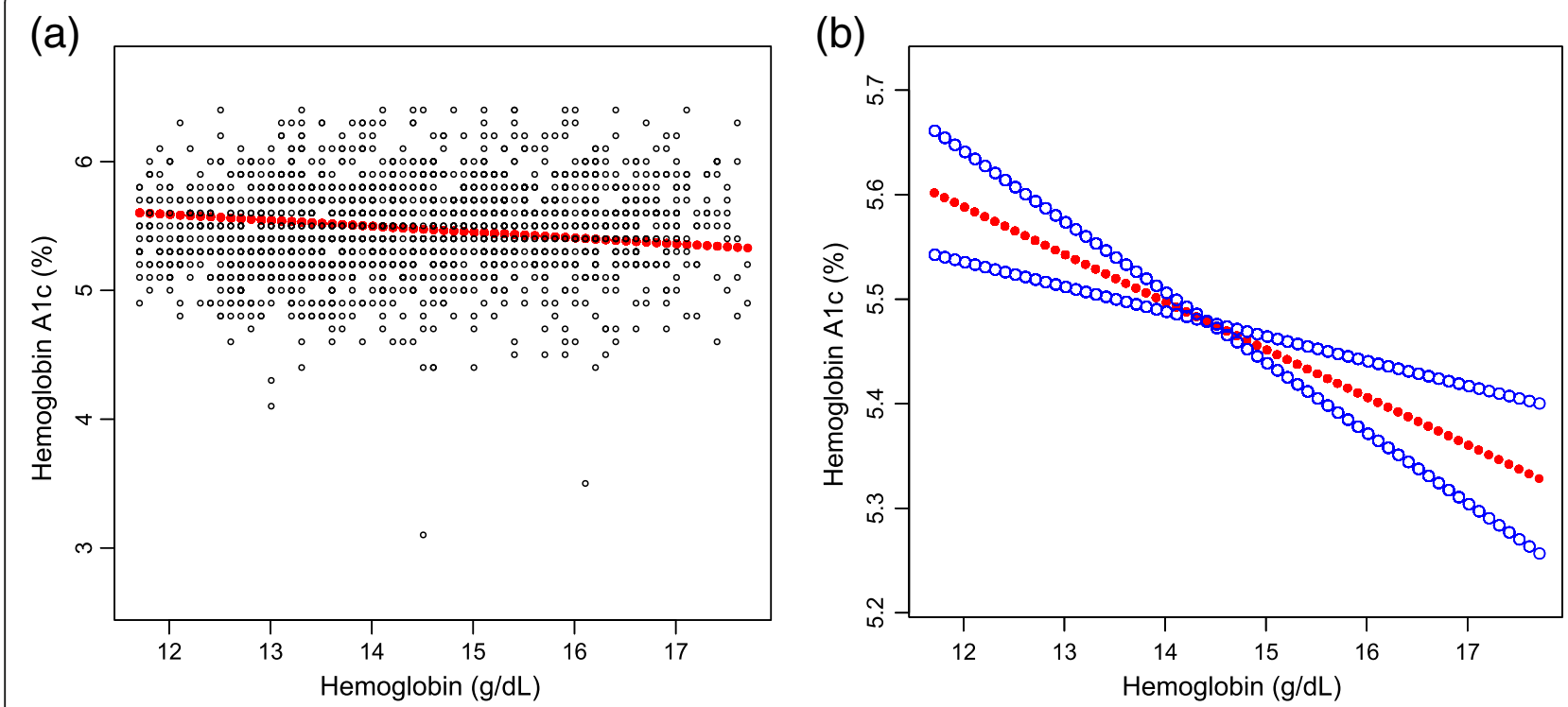

Fig. 2 The association between hemoglobin and hemoglobin A1c. a Each black point represents a sample. b Solid rad line represents the smooth curve fit between variables. Blue bands represent the $95 \%$ of confidence interval from the fit. Age, sex, smoking behavior, alcohol consumption, body mass index, blood glucose, white blood cell count, and red blood cell count were adjusted 


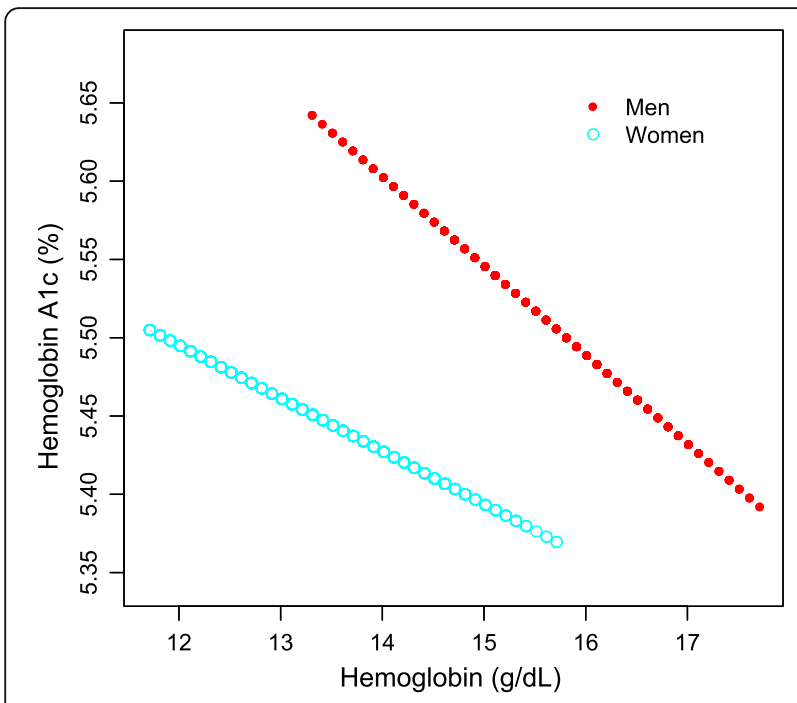

Fig. 3 The association between hemoglobin and hemoglobin A1c, stratified by sex. Age, smoking behavior, alcohol consumption, body mass index, blood glucose, white blood cell count, and red blood cell count were adjusted

are not generalizable to these populations. Third, although we adjusted for several important potential confounders, other potential confounding factors, including hemoglobinopathies, iron deficiency, drug use, menstruation status, hypothyroidism, and chronic kidney disease, may have introduced bias. The results of our study differed according to the model used, as the association between $\mathrm{Hb}$ and HbA1c levels was affected by the choice of the covariates included in the model, such as the RBC count. However, conditions such iron deficiency and altered RBC lifespan, which may

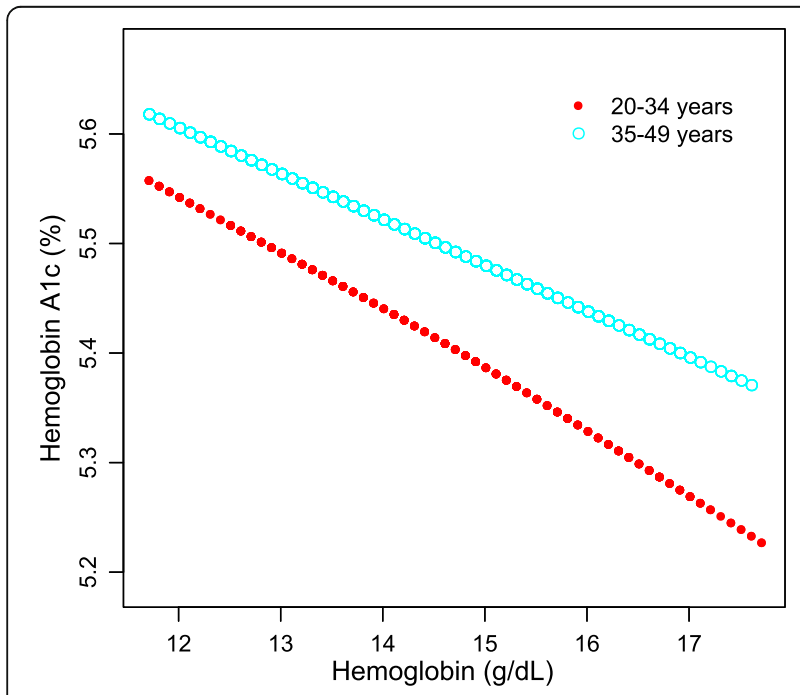

Fig. 4 The association between hemoglobin and hemoglobin A1c, stratified by age. Age, sex, smoking behavior, alcohol consumption, body mass index, blood glucose, white blood cell count, and red blood cell count were adjusted also have important effects on the association between $\mathrm{Hb}$ and HbAlc levels, were not included in the CHNS surveys. Therefore, further large sample prospective studies that include measurements of these additional variables are warranted.

\section{Conclusions}

Our findings revealed that $\mathrm{Hb}$ levels within the normal range were negatively associated with $\mathrm{HbA1c}$ levels among Chinese non-diabetes adults. Confounding factors, such as RBC counts, can affect the association between $\mathrm{Hb}$ and $\mathrm{HbA} 1 \mathrm{c}$ levels.

\section{Supplementary Information}

The online version contains supplementary material available at https://doi. org/10.1186/s12902-021-00704-X.

Additional file 1: Table S1. Univariate analysis of the associations of each covariate with $\mathrm{HbA} 1 \mathrm{c}$.

\section{Abbreviations}

Hb: Hemoglobin; HbA1c: Hemoglobin A1c; CHNS: the China Health and Nutrition Survey; CCDC: the Chinese Center for Disease Control and Prevention; UNC: the University of North Carolina at Chapel Hill; BMI: Body mass index; ALT: Alanine aminotransferase; WBC: White blood cell; RBC: Red blood cell; PLT: Platelet

\section{Acknowledgements}

The authors appreciate the time and effort given by participants during the data collection phase of the CHNS project.

\section{Authors' contributions}

$\mathrm{YL}$, and $\mathrm{ZHL}$ contributed to data collection, analysis and writing of the manuscript. ZXZ contributed to study design, writing and editing of the manuscript. All authors have read and approved the manuscript.

Funding

This study received no funding.

\section{Availability of data and materials}

Details of the study design, sampling strategies and data are available at the World Wide Web site (https://www.cpc.unc.edu/projects/china). The datasets used and/or analysed during the current study are available from the corresponding author on reasonable request.

\section{Ethics approval and consent to participate}

The site (https://www.cpc.unc.edu/projects/china) uses the Open Source Content Management System Plone and has been designed to be completely accessible and usable, working in accordance with the Web Content Accessibility Guidelines (WCAG v1.0). The China Health and Nutrition Survey is an international collaborative project between the Carolina Population Center at the University of North Carolina at Chapel Hill and National Institute of Nutrition and Food Safety at the Chinese Center for Disease Control and Prevention. In 2009, the Department of Laboratory Medicine of China-Japan Friendship Hospital, Ministry of Health joined this project as the lead agency for the collection, storage and analysis of biospecimens. All protocols were approved by the Institutional Review Board of National Institute of Nutrition and Food Safety at Chinese Center for Disease Control and Prevention, the Carolina Population Center at the University of North Carolina at Chapel Hill, and the China-Japan Friendship Hospital, Ministry of Health, China. The datasets from the official CHNS website are publicly-available and downloadable from the Website (https:// www.cpc.unc.edu/projects/china/data/datasets). A simple registration is required in order to access the data downloads. Hence, the need for ethics approval was waived by the Institutional Review Board of Xiaoshan Affiliated Hospital of Wenzhou Medical University. The CHNS provides respondents 
guarantees of their privacy and confidentially. All participants provided written informed consent for the use of their data in research. Details about the study design are available elsewhere [10].

\section{Consent for publication}

Not applicable.

\section{Competing interests}

The authors declare that they have no competing interests.

\section{Author details}

${ }^{1}$ Department of Emergency, Xiaoshan Affiliated Hospital of Wenzhou Medical University, Hangzhou 311200, Zhejiang, China. ${ }^{2}$ Department of General Surgery, Xiaoshan Affiliated Hospital of Wenzhou Medical University, Hangzhou 311200, Zhejiang, China. ${ }^{3}$ Department of Osteoporosis Care and Control, Xiaoshan Affiliated Hospital of Wenzhou Medical University, Hangzhou 311200, Zhejiang, China. ${ }^{4}$ Clinical Research Center, Xiaoshan Affiliated Hospital of Wenzhou Medical University, Hangzhou 311200 Zhejiang, China.

Received: 21 October 2020 Accepted: 18 February 2021

Published online: 27 February 2021

\section{References}

1. Seino Y, Yamazaki Y, Yabe D. The Asian Association for the Study of Diabetes (AASD): the first ten years and the next ten years. J Diab Invest. 2020.

2. Tafere GG, Wondafrash DZ, Zewdie KA, Assefa BT, Ayza MA. Plasma adipsin as a biomarker and its implication in type 2 diabetes mellitus. Diab Metab Syndr Obes. 2020;13:1855-61.

3. Cole JB, Florez JC. Genetics of diabetes mellitus and diabetes complications. Nat Rev Nephrol. 2020;16(7):377-90

4. Laakso M. Biomarkers for type 2 diabetes. Mol Metab. 2019;27s(Suppl): S139-s146.

5. Eyth E, Naik R. Hemoglobin A1C. In: StatPearls. edn. Treasure Island: StatPearls Publishing Copyright (c) 2020, StatPearls Publishing LLC; 2020

6. English $\mathrm{E}$, Lenters-Westra E. HbA1c method performance: the great success story of global standardization. Crit Rev Clin Lab Sci. 2018;55(6):408-19.

7. Gilstrap LG, Chernew ME, Nguyen CA, Alam S, Bai B, McWilliams JM, Landon $\mathrm{BE}$, Landrum MB. Association between clinical practice group adherence to quality measures and adverse outcomes among adult patients with diabetes. JAMA Netw Open. 2019;2(8):e199139.

8. Classification and diagnosis of diabetes: standards of medical care in diabetes-2020. Diab Care. 2020;43(Suppl 1):S14-s31.

9. Katwal PC, Jirjees S, Htun ZM, Aldawudi I, Khan S. The effect of anemia and the goal of optimal HbA1c control in diabetes and non-diabetes. Cureus. 2020;12(6):e8431

10. Popkin BM, Du S, Zhai F, Zhang B. Cohort profile: the China health and nutrition survey--monitoring and understanding socio-economic and health change in China, 1989-2011. Int J Epidemiol. 2010;39(6):1435-40.

11. A list of biomarkers and methods used to measure them, China Health and Nutrition Survey (CHNS). https://www.cpc.unc.edu/projects/china/data/data sets/Biomarker_Methods.pdf

12. Manual for Specimen Collection and Processing, China Health and Nutrition Survey (CHNS). https://www.cpc.unc.edu/projects/china/data/datasets/ Blood\%20Collection\%20Protocol_English.pdf

13. 2.Classification and diagnosis of diabetes: standards of medical care in diabetes-2019. Diab Care. 2019:42(Suppl 1):S13-s28.

14. Survey data, China Health and Nutrition Survey (CHNS). https://www.cpc. unc.edu/projects/china/data

15. Sahay M, Kalra S, Badani R, Bantwal G, Bhoraskar A, Das AK, Dhorepatil B, Ghosh S, Jeloka T, Khandelwal D, et al. Diabetes and anemia: International Diabetes Federation (IDF) - Southeast Asian Region (SEAR) position statement. Diab Metab Syndr. 2017;11(Suppl 2):S685-s695.

16. Intra J, Limonta G, Cappellini F, Bertona M, Brambilla P. Glycosylated hemoglobin in subjects affected by iron-deficiency anemia. Diab Metab J. 2019:43(4):539-44.

17. Silva JF, Pimentel AL, Camargo JL. Effect of iron deficiency anaemia on $\mathrm{HbA1c}$ levels is dependent on the degree of anaemia. Clin Biochem. 2016; 49(1-2):117-20.
18. Brooks AP, Metcalfe J, Day JL, Edwards MS. Iron deficiency and glycosylated haemoglobin A. Lancet (London, England). 1980:2(8186):141.

19. Ford ES, Cowie CC, Li C, Handelsman Y, Bloomgarden ZT. Iron-deficiency anemia, non-iron-deficiency anemia and $\mathrm{HbA1C}$ among adults in the US. J Diab. 2011;3(1):67-73.

20. Çetinkaya Altuntaş S, Evran M, Gürkan E, Sert M, Tetiker T. HbA1c level decreases in iron deficiency anemia. Wien Klin Wochenschr. 2020.

21. Grossman A, Gafter-Gvili A, Schmilovitz-Weiss H, Koren-Morag N, Beloosesky Y. Weiss A. Association of glycated hemoglobin with hemoglobin levels in elderly nondiabetic subjects. Eur J Intern Med. 2016;36:32-5.

22. Campbell L, Pepper T, Shipman K. HbA1c: a review of non-glycaemic variables. J Clin Pathol. 2019;72(1):12-9.

23. Beck RW, Connor CG, Mullen DM, Wesley DM, Bergenstal RM. The fallacy of average: how using $\mathrm{HbA}$ (1c) alone to assess glycemic control can be misleading. Diab Care. 2017:40(8):994-9.

24. English E, Idris I, Smith G, Dhatariya K, Kilpatrick ES, John WG. The effect of anaemia and abnormalities of erythrocyte indices on $\mathrm{HbA} 1 \mathrm{c}$ analysis: a systematic review. Diabetologia. 2015;58(7):1409-21.

\section{Publisher's Note}

Springer Nature remains neutral with regard to jurisdictional claims in published maps and institutional affiliations.
Ready to submit your research? Choose BMC and benefit from:

- fast, convenient online submission

- thorough peer review by experienced researchers in your field

- rapid publication on acceptance

- support for research data, including large and complex data types

- gold Open Access which fosters wider collaboration and increased citations

- maximum visibility for your research: over $100 \mathrm{M}$ website views per year

At BMC, research is always in progress.

Learn more biomedcentral.com/submissions 